\title{
FOREIGN CURRENCY FUTURES
}

\author{
Robert J. HODRICK \\ Kellogg Graduate School of Management, Northwestern University, Evanston, IL 6020I, USA \\ National Bureau of Economic Research \\ Sanjay SRIVASTAVA* \\ Graduate School of Industrial Administration, Carnegie-Mellon University, USA
}

Received December 1985

\begin{abstract}
The theoretical nature of risk premiums in foreign currency futures markets is derived and sludied empirically. Estimation problems encountered in using futures data are discussed. Since forward rates and futures prices have been found to be approximately equal, and because risk premiums in forward markets are highly variable, consistency of the data requires time variation in daily risk premiums in the futures market. Unbiasedness of daily futures prices as predictors of the following day's futures price is rejected for all currencies. Reconciliation of daily and monthly data requires positive serial correlation in daily risk premiums.
\end{abstract}

\section{Introduction}

The purpose of this paper is to investigate the nature of risk and return in futures markets for foreign exchange. The paper integrates and extends two relatively unrelated strands of literature. On the one hand, we draw on the predominantly empirical literature on the efficiency of the forward foreign exchange market for motivation and econometric specifications, and on the other hand, we integrate into the international finance literature the predominantly theoretical results on the determination of commodity futures prices and the differences between a futures price and a forward price.

The empirical literature on the efficiency of the forward foreign exchange market is discussed in Hodrick and Srivastava (1984). There, we identify several positions within the profession regarding the evidence on efficiency.

\footnotetext{
*This research was supported by a grant from the Center for the Study of Futures Prices at Columbia University. We thank them for the support. We also thank Lars Hansen, Ravi Jagannathan and Richard Levich for helpful discussions and Jim Clouse and Vinay Swaroop for excellent assistance in the empirical research. This paper was presented at the 1985 N.B.E.R. Summer Institute, the Universities of California at Los Angeles and San Diego, the University of Chicago, New York University and Northwestern University. We thank the participants of the seminars for their comments and suggestions.
} 
We first note the general confusion that has permeated this literature because efficiency is often identified with the proposition that the forward rate is an unbiased predictor of the future spot rate. The unbiasedness hypothesis is rejected in many empirical studies for maturities as short as a day [Dooley and Shafer (1983)] or a week [Cumby and Obstfeld (1981), Hsieh (1984)], to more traditional maturities of one month [Bilson (1981), Hansen and Hodrick (1983, Fama (1984)], or three months [Hansen and Hodrick (1980, Cumby and Obstfeld (1984)]. The reaction to these empirical findings has not been the uniform acceptance of a particular model of risk premiums. Instead, three alternative perspectives have emerged. One perspective questions the findings because of doubt about the statistical validity of the tests that are invariably based on asymptotic distribution theory. Another perspective accepts the validity of the statistical findings but claims that they are evidence of market inefficiency. Most financial economists continue to search for a model of time varying risk premiums that is consistent with the data. Unfortunately, progress in this search has been slow, and several dead ends appear to have been encountered. ${ }^{1}$

If the magnitude of the variation in estimated risk premiums relative to the variation in expected rates of exchange rates were small, perhaps the unbiasedness hypothesis could be treated as an approximation that is nearly true. This idea is contradicted, though, by the recent studies using monthly data by Fama (1984) and Hodrick and Srivastava (1986). These studies treat the forward premium as the sum of two unobservable components, the expected rate of depreciation and a normalized risk premium. While the two studies differ in methodology and in interpretation of the empirical results, both demonstrate that the risk premium in the forward foreign exchange market has a larger variance than that of the expected rate of change of the spot exchange rate. These statements are, of course, conditional on the validity of the statistical tests in the sample sizes employed in the studies.

Since futures prices of foreign exchange also can be described as containing predictions of future exchange rates plus risk premiums, this paper seeks to determine whether the rejection of the unbiasedness hypothesis and the nature of time variation in risk premiums found in forward markets carries over into the futures market. The availability of daily futures also makes this market an attractive one for investigation of the potential importance of small sample size in explaining the results from the forward market.

It is well known that futures contracts differ in several ways from forward contracts. Forward prices are quoted in an interbank market for delivery at a fixed time of maturity that is typically one, three, six, or twelve months. Futures prices are quoted at an organized exchange like the International

\footnotetext{
'Recent work by Korajczyk (1985) and Mark (1985) does show promise in relating rejections of unbiasedness to formal models of risk premiums that include market fundamentals.
} 
Monetary Market (IMM) in Chicago. Contracts are traded for delivery on the third Wednesday of March, June, September, and December, and typically there are four contracts outstanding at a point in time. Futures contracts are also marked to market daily which induces a theoretical reason why forward prices and futures prices for delivery on the same day in the future may differ. The influence of marking to market on the futures price was first discussed by Black (1976) and has been modeled by Cox, Ingersoll and Ross (1981), Richard and Sundaresan (1981), and French (1983).

Section 2 of the paper extends the theoretical discussion in Hodrick and Srivastava (1984) to the determination of futures prices for foreign exchange within the context of a simple general equilibrium model developed by Lucas (1982). The theoretical difference between a forward contract for foreign exchange and a futures contract is examined.

Although in theory there may be a difference between forward prices and futures prices for delivery on the same day in the future, the initial empirical work in this area by Cornell and Reinganum (1981) found very little difference between the two speculative prices. Consequently, if the relation between expected spot rates and forward rates is characterized by a time varying risk premium, futures prices must be biased predictors of the next day's futures price in contrast to Samuelson's (1965) martingale model.

Section 3 of the paper examines empirically whether the econometric techniques that were powerful enough to reject the unbiasedness hypothesis in the forward market are also powerful enough to find these movements in daily risk premiums in the futures market.

The last section of the paper provides an interpretation of the empirical findings, examines what appears to be needed to reconcile the findings with previous research, and discusses possible directions of future research in this area.

\section{Futures pricing theory}

In this section of the paper we extend international intertemporal asset pricing models such as the Lucas (1982) model to consider the pricing of the futures contracts for foreign currency by examining the analysis in Cox, Ingersoll and Ross (1981) and Richard and Sundaresan (1981) who discuss pricing of futures on commodities. When necessary for clarity, we adopt a dating convention that dates all variables with a primary subscript indicating when they enter the agents' information set and with a secondary subscript to indicate how far into the future or past it is necessary to go in order to define the concept appropriately.

Let $S_{t}$ be the spot price of foreign currency in terms of dollars at time $t$, and let $G_{t, k}$ be the forward price of foreign currency set at time $t$ for delivery at time $t+k$. Also, let $R_{t, j}$ be the known dollar return from investing a dollar 
at time $t$ in a $j$-period risk-free bill. Then, Cox, Ingersoll and Ross (1981, Proposition 1) use arbitrage arguments to demonstrate that $G_{t, k}$ is the present value of a time $t+k$ payoff equal to $S_{t+k} R_{t, k}$. The arbitrage strategy involves investing $G_{t, k}$ dollars in the $k$-period bill, which gives return $G_{t, k} R_{t, k}$ at time $t+k$, and making $R_{t, k}$ forward contracts, which are costless to enter into at time $t$ and have time $t+k$ payoff of $S_{t+k}-G_{t, k}$ per contract. If $F_{t, k}$ is the futures price of foreign currency in terms of dollars at time $t$ with maturity date $t+k$, then Cox, Ingersoll and Ross (1981, Proposition 2) demonstrate that $F_{t, k}$ is the present value at $t$ of a payoff of $S_{t+k} \prod_{j=t}^{t+k-1} R_{j, 1}$ at time $t+k$. The proof of this proposition incorporates the fact that futures contracts are marked to market which provides the investor with a sequence of intermediate cash flows between $t$ and $t+k$. Marking to market requires that the long (short) investor in a contract maturing at time $t+k$ receives (pays) the amount $\left(F_{j, n}-F_{j-1, n+1}\right)$ if it is positive (negative) at time $j=t+1, \ldots, t+k$ where $n=t+k-j$ is the number of periods remaining on the futures contract. The arbitrage strategy involves investing $F_{t, k}$ dollars in the oneperiod bill and rolling the proceeds forward while making futures contracts at time $t+h$ equal to the product of the short rates between $t$ and $t+h$ and reinvesting the profits or losses in the sequence of one-period bills.

Present values are determined by asset pricing paradigms. Consider an asset with dollar price $V_{t}$ and time $t+k$ payoff of $V_{t+k}+D_{t+k}$, where $D_{t+k}$ is a dividend or coupon payment. The forgone marginal utility of making the investment is $V_{t} \pi_{t} E_{t}\left(M U_{t}\right)$, where $\pi_{t}$ is the purchasing power of a dollar at time $t$, which has units of numeraire good per dollar, and where $E_{t}\left(M U_{t}\right)$ denotes the conditional expectation of the marginal utility of the numeraire good in a possibly non-time separable utility function. The expected marginal utility from the payoff of the investment is $E_{t}\left\{\left(V_{t+k}+D_{t+k}\right) \pi_{t+k} E_{t+k}\left(M U_{t+k}\right)\right\} .^{2}$ It depends on the purchasing power of the dollar at time $t+k$ and on the expected marginal utility at that time.

Equating the marginal cost of the investment to its expected marginal benefit produces an expression that must be satisfied in equilibrium by all returns:

$$
1=E_{t}\left(Q_{t+k, k} r_{t+k, k}\right),
$$

where $r_{t+k, k}=\left(V_{t+k}+D_{t+k}\right) / V_{t}$ is a nominal dollar return between time $t$ and

\footnotetext{
2The development of the preceding argument does not discuss how money is formally introduced into the model in order that it will not be an asset whose rate of return is dominated. Townsend (1983) and Lucas (1984) explore the implications of cash-in-advance constraints for a subset of goods. Their theoretical results indicate that the pricing ol assets with nominal payoffs is sensitive to this issue. Svensson (1985) explores an alternative timing for the acquisition of goods and assets and reaches similar conclusions. Singleton (1985) discusses how one might address these issues econometrically.
} 
time $t+k$, and where

$$
Q_{t+k, k}=\pi_{t+k} E_{t+k}\left(M U_{t+k}\right) / \pi_{t} E_{t}\left(M U_{t}\right)
$$

is the intertemporal marginal rate of substitution of dollars between time $t$ and time $t+k$.

As Richard and Sundaresan (1981) note, the asset pricing paradigm in (1) provides a present value operator that converts dollar payoffs at $t+k$ into dollar values at $t$. Since the forward price, $G_{t, k}$, is the present value of the payoff $S_{t+k} R_{t, k}$ and the futures price, $F_{t, k}$, is the present value of $S_{t+k} \prod_{j=t}^{t+k-1} R_{j, 1}$, the following equilibrium pricing relationships are dictated by (1):

$$
G_{t, k}=E_{t}\left(Q_{t+k, k} S_{t+k} R_{t, k}\right)
$$

and

$$
F_{t, k}=E_{t}\left(Q_{t+k, k} \prod_{j=t}^{t+k-1} R_{j, 1} S_{t+k}\right)
$$

If short-term interest rates were deterministic, arbitrage would require the known $k$-period return $R_{t, k}$ to be equal to the product of the $k$ one-period returns, $\prod_{j=1}^{t+k-1} R_{j, 1}$. Examination of (3) and (4) indicates that forward prices and futures prices would be identical in this case, as Black (1976) noted, because $R_{t, k}$ and $\prod_{j=t}^{t+k-1} R_{j, 1}$ would both be elements of the time $t$ information set and could be divided out of the right-hand sides of (3) and (4).

Richard and Sundaresan (1981) note that (3) and (4) provide two reasons why futures prices may differ from forward prices. First, the known return, $R_{t, k}$ is generally not equal to the product of the $k$ one-period returns, $\prod_{j=1}^{t i k-1} R_{j, 1}$, and second, the product of the intertemporal marginal rate of substitution of the dollar and the exchange rate, $Q_{t+k, k} S_{t+k}$, may be correlated with the product of the short rates. Applying a covariance decomposition to (3) and (4), yields:

$$
\begin{aligned}
G_{t, k} & =E_{t}\left(Q_{t+k, k} R_{t, k}\right) E_{t}\left(S_{t+k}\right)+C_{t}\left(Q_{t+k, k} R_{t, k} ; S_{t+k}\right) \\
& =E_{t}\left(S_{t+k}\right)+C_{t}\left(Q_{t+k, k} R_{t, k} ; S_{t+k}\right)
\end{aligned}
$$

and

$$
\begin{aligned}
F_{t, k} & =E_{t}\left(Q_{t+k, k} \prod_{j=t}^{t+k-1} R_{j, 1}\right) E_{t}\left(S_{t+k}\right)+C_{t}\left(Q_{t+k, k} \prod_{j=t}^{t+k-1} R_{j, 1} ; S_{t+k}\right) \\
& =E_{t}\left(S_{t+k}\right)+C_{t}\left(Q_{t+k, k} \prod_{j=t}^{t+k-1} R_{j, 1} ; S_{t+k}\right),
\end{aligned}
$$


where $C_{t}(X ; Y)$ is the conditional covariance of two random variables $X$ and $Y$. The second lines of (5) and (6) follow because the $k$-period long return and the product of the $k$ short returns must both satisfy (1) in equilibrium. Both forward prices and futures prices of foreign exchange are generally biased predictors of future spot rates as (5) and (6) indicate. If the conditional covariances in (5) and (6) were constant, then forward and futures prices would be characterized by a constant unconditional bias. Obviously, if the conditional distribution of the random variables in (5) and (6) varies over time, no such unconditional bias need characterize the data and a time varying risk premium may be present.

\section{Time varying daily risk premiums}

Cornell and Reinganum (1981) first compared forward rates to futures prices for delivery on the same day. They concluded that the two prices are essentially the same given the nature of transactions costs in these markets. ${ }^{3}$ This suggests that given the strong rejection of the unbiasedness hypothesis in the forward market, similar findings ought to be found in the futures data. In this section we investigate the properties of futures prices as predictors of futures prices in the future.

Samuelson (1965) argued that the sequence of futures prices in an efficient market would be a martingale with $F_{t, k}=E_{t}\left(F_{t+1, k-1}\right)$. If this were true, we know that the futures prices, in contrast to forward prices, would be unbiased predictors of future spot prices. This is easily demonstrated by repeated application of the law of iterated expectations and by use of the arbitrage argument, $F_{t+k, 0}=S_{t+k}$. If $F_{t, k}=E_{t}\left(F_{t+1, k-1}\right)$ and $F_{t+1, k-1}=$ $E_{t+1}\left(F_{t+2, k-2}\right)$, then

$$
F_{t, k}=E_{t}\left[E_{t+1}\left(F_{t+2, k-2}\right)\right]=E_{t}\left(F_{t+2, k-2}\right) .
$$

Since the unbiasedness hypothesis is easily rejected for forward exchange rates and since no evidence is available to indicate a strong difference between futures prices and forward prices, it must be the case that Samueison's argument contains a joint hypothesis. Indeed, if risk premiums

\footnotetext{
${ }^{3}$ In Hodrick and Srivastava (1985) we report a comparison between futures prices and forward prices for the five currencies in our study. Our data contained an approximate two-hour difference between forward rates measured at 9:30 a.m. in San Francisco (11:30 a.m. in Chicago) and futures prices measured at IMM closing (between 1:16 p.m. and 1:26 p.m.) in Chicago. Cornell and Reinganum (1981) obtained data directly from the IMM. Their forward rates were measured at 1:00 p.m. Chicago time and their futures prices were closing. Unless one assumes conditional homoscedasticity of changes in futures prices, which appears not to be an appropriate assumption, the value of any comparison not at exactly the same moment in time is open to question. Although we reported some relatively large differences between the two prices, our conclusion was that no evidence existed to contradict the results of Cornell and Reinganum.
} 
are not constant, then Samuelson's argument must be modified, as we now demonstrate. ${ }^{4}$

Consider the futures price of foreign exchange at time $t+1$ with $k-1$ days to maturity. From (4) we know that

$$
F_{t+1, k-1}=E_{t+1}\left(Q_{t+k, k-1} S_{t+k} \prod_{j=t+1}^{t+k-1} R_{j, 1}\right) .
$$

Also, from the definition of the intertemporal marginal rate of substitution we know that

$$
Q_{t+k, k}=Q_{t+k, k-1} Q_{t+1,1},
$$

since from (2)

$$
Q_{t+k \cdot k-1}=\pi_{t+k} E_{t+k}\left(M U_{t+k}\right) / \pi_{t+1} E_{t+1}\left(M U_{t+1}\right)
$$

and

$$
Q_{t+1,1}=\pi_{t+1} E_{t+1}\left(M U_{t+1}\right) / \pi_{t} E_{t}\left(M U_{t}\right) .
$$

Proposition 1 . The futures price, $F_{t, k}$, is equal to the time $t$ conditional expectation of $F_{t+1, k-1}$ plus a risk premium.

Proof. From (4), (8), and (9) find

$$
F_{t, k}=E_{t}\left[Q_{t+k, k-1} Q_{t+1,1} S_{t+k} \prod_{j=t+1}^{t+k-1} R_{j, 1} R_{t, 1}\right] .
$$

Covariance decomposition of (12) gives:

$$
\begin{aligned}
F_{t, k}= & E_{t}\left(Q_{t+k, k-1} S_{t+k} \prod_{j=t+1}^{t+k-1} R_{j, 1}\right) E_{t}\left(Q_{t+1,1} R_{t, 1}\right) \\
& +C_{t}\left(Q_{t+k, k-1} S_{t+k} \prod_{j=t+1}^{t+k-1} R_{j, 1} ; Q_{t+1,1} R_{t, 1}\right) .
\end{aligned}
$$

From (1), (8) and the law of iterated expectations, (13) becomes:

$$
F_{t, k}=E_{t}\left(F_{t+1, k-1}\right)+C_{t}\left(F_{t+1, k-1} ; Q_{t+1,1} R_{t, 1}\right) \text {. Q.E.D. }
$$

${ }^{4}$ Samuelson (1965) was clear about the nature of his joint hypothesis although he seemed more concerned about the neglect of interest rates than of risk aversion. 
Whenever the conditional covariance in (14) is not a time invariant function, there will be time varying bias in daily futures prices. The next part of this section investigates statistical tests of the proposition that futures prices are unbiased predictors of the futures price on the next business day.

\subsection{The econometric specification}

Consider the null hypothesis of unbiasedness in daily prices given in (15):

$$
E_{t}\left(F_{t+1, k-1}\right)=F_{t, k} .
$$

Since $S_{t}$ is in the information set at time $t$, we may write

$$
E_{t}\left[\left(F_{t+1, k-1}-S_{t}\right) / S_{t}\right]=\left(F_{t, k}-S_{t}\right) / S_{t},
$$

where the transformation makes it more likely that the statistical assumption of stationarity of the data that is necessary for convergence of the asymptotic distributions of parameter estimates is satisfied. ${ }^{5}$

In order to conserve notation let $y_{t+1}=\left(F_{t+1, k-1}-S_{t}\right) / S_{t}$, and let $x_{1}=$ $\left(F_{t, k}-S_{t}\right) / S_{t}$. Since $y_{t+1}=E_{t}\left(y_{t+1}\right)+\varepsilon_{t+1}$, where $\varepsilon_{t+1}$ is the forecast error that is orthogonal to time $t$ information, a test of (16) can be conducted in the usual way by assuming rational expectations and by defining the function $h\left(y_{t+1}, x_{t}, \delta_{0}\right) \equiv \varepsilon_{t+1}$ as

$$
h\left(y_{t+1}, x_{t}, \delta_{0}\right)=y_{t+1}-\alpha-\beta x_{t},
$$

where $\delta_{0}$ is the true parameter vector $(\alpha, \beta)$ and the null hypothesis is $\alpha=0$ and $\beta=1$. Tests of these hypotheses are performed for five currencies in table 1. Estimation and testing is accomplished with Hansen's (1982) Generalized Method of Moments (GMM). A nice feature of the GMM procedure is that no additional auxiliary assumption of conditional homoscedasticity need be made in constructing the covariance matrix of the parameter estimates. ${ }^{6}$

Under the null hypothesis $\varepsilon_{t+1}$ can be interpreted as the disturbance term in an econometric estimation. The model provides orthogonality conditions that can be used to estimate $\alpha$ and $\beta$ in (17). We assume that $\varepsilon_{t+1}$ has a finite second moment although we do not impose an assumption of conditional homoscedasticity. Let $z_{t}^{\prime}$ be the row vector $\left(1, x_{t}\right)$ of instruments that will be

\footnotetext{
${ }^{5}$ The spot rate data are from Data Resources, Inc., which obtains them from Bank of America in San Francisco. The data are on line by 9:30 a.m. San Francisco time. Hence, they are measured approximately two hours prior to $F_{1, k}$.

${ }^{6}$ Evidence in Cumby and Obstfeld (1984), Hodrick and Srivastava (1984), Hsieh (1984) and Domowitz and Hakkio (1985) suggests that conditional heteroscedasticity is present in monthly data.
} 
Table 1

Full sample single equation estimates $\left.\left(F_{t+1, k-1}-S_{t}\right) / S_{t}=\alpha+\beta\left[F_{t, k}-S_{t}\right) / S_{t}\right]+\varepsilon_{t+1}$.

\begin{tabular}{|c|c|c|c|c|c|}
\hline Currency & $\hat{\alpha}$ & $\hat{\beta}$ & $R^{2}$ & Test $\beta=1$ & SEE \\
\hline I. Japanese yen & $\begin{array}{c}0.0001 \\
(0.0001) \\
{[0.3747]}\end{array}$ & $\begin{array}{c}0.9496 \\
(0.0158) \\
{[0.0000]}\end{array}$ & 0.72 & $\begin{array}{l}10.2167 \\
{[0.0014]}\end{array}$ & 0.0063 \\
\hline 2. Deutschemark & $\begin{array}{c}0.0002 \\
(0.0001) \\
{[0.1940]}\end{array}$ & $\begin{array}{c}0.9292 \\
(0.0290) \\
{[0.0000]}\end{array}$ & 0.46 & $\begin{array}{c}5.9730 \\
{[0.0145]}\end{array}$ & 0.0061 \\
\hline 3. U.K. pound & $\begin{array}{c}-0.0003 \\
(0.0001) \\
{[0.0206]}\end{array}$ & $\begin{array}{c}0.9330 \\
(0.0195) \\
{[0.0000]}\end{array}$ & 0.58 & $\begin{array}{l}11.7977 \\
{[0.0006]}\end{array}$ & 0.0059 \\
\hline 4. Canadian dollar & $\begin{array}{c}-0.0001 \\
(0.0001) \\
{[0.0089]}\end{array}$ & $\begin{array}{c}0.9412 \\
(0.0175) \\
{[0.0000]}\end{array}$ & 0.61 & $\begin{array}{l}11.2927 \\
{[0.0008]}\end{array}$ & 0.0024 \\
\hline 5. Swiss franc & $\begin{array}{c}-0.0006 \\
(0.0002) \\
{[0.0085]}\end{array}$ & $\begin{array}{c}0.9191 \\
(0.0241) \\
{[0.0000]}\end{array}$ & 0.53 & $\begin{array}{l}11.2870 \\
{[0.0008]}\end{array}$ & 0.0075 \\
\hline
\end{tabular}

Notes: The sample period is 1 June 1973 to 8 December 1983 and contains 2420 observations. Standard errors are in parentheses, and marginal levels of significance are in brackets. The test statistic in the column labelled Test $\beta=1$ is $[(1-\hat{\beta}) / \sigma(\hat{\beta})]^{2}$, where $\sigma(\hat{\beta})$ is the standard error of the estimated coefficient. The test statistic is distributed as a chisquare with one degree of freedom. The marginal levels of significance below the coefficients concern the hypothesis that the value of the coefficient is zero.

used in the estimation. Then, following Hansen and Singleton (1982), define the function $f$ by

$$
f\left(y_{t+1}, x_{t}, \delta\right)=h\left(y_{t+1}, x_{t}, \delta\right) \otimes z_{t}
$$

The model implies:

$$
E\left[f\left(y_{t+1}, x_{t}, \delta_{0}\right)\right]=0,
$$

which is a set of two orthogonality conditions when $f$ is evaluated at the true parameter vector. The GMM estimator exploits the sample moment of (19) defined by

$$
g_{T}(\delta)=\left(\frac{1}{T}\right) \sum_{t=1}^{T} f\left(y_{t+1}, x_{t}, \delta\right)
$$

for a sample of size $T$. The choice of $\hat{\delta}$ in the GMM procedure requires 
minimization of the criterion function,

$$
J_{T}(\delta)=g_{T}(\delta)^{\prime} W_{T} g_{T}(\delta),
$$

for an appropriately chosen weighting matrix $W_{T}$ that is $2 \times 2$ and symmetric.

Notice that in this case

$$
g_{T}(\delta)^{\prime}=(y-Z \delta)^{\prime} Z / T
$$

where $y$ is a $T$-dimensional vector of observations on $y_{t+1}$ and $Z$ is a $T \times 2$ matrix of observations on $z_{t}^{\prime}$. Hence, minimization of (21) produces the ordinary least squares (OLS) estimator

$$
\delta_{T}=\left(Z^{\prime} Z\right)^{-1} Z^{\prime} y,
$$

but the OLS standard errors are not appropriate. Cumby, Huizinga and Obstfeld (1983) demonstrate that any GMM estimator in this linear environment that exploits the orthogonality conditions (19) has the same asymptotic distribution. They demonstrate that

$$
\sqrt{ } T\left(\delta_{T}-\delta_{0}\right) \stackrel{\text { i.d. }}{\longrightarrow} N\left(0, D_{0}^{-1} \Omega D_{0}^{-1}\right),
$$

where $\Omega=\lim _{T \rightarrow \infty}(1 / T) E\left(Z^{\prime} \varepsilon \varepsilon^{\prime} Z\right)$, $\varepsilon$ is the $T$-dimensional vector of true errors, $\varepsilon_{t}$, and $D_{0}=\operatorname{plim}\left(Z^{\prime} Z / T\right)$.

It is interesting that the moment estimator of $\Omega$, given by

$$
\Omega_{T}=(1 / T) \sum_{t=1}^{T} z_{t} z_{t}^{\prime} \hat{\varepsilon}_{t+1}^{2}
$$

is a consistent estimator of $\Omega$ even though the daily futures data are not covariance stationary. A similar argument holds for $D_{0}$ and its estimator $D_{T}=\left(Z^{\prime} Z / T\right)$.

We follow Jagannathan $(1983,1985)$ in deriving the asymptotic distribution of GMM estimators that arise when using data from futures markets with their peculiar contract structure. To understand the problem imagine a fictional vector of daily observations on futures premiums defined in the right-hand side of (16) with between 1 and $K$ days to maturity, where $K$ is the longest time period considered in the actual data. Let this $K$-dimensional vector be denoted $X_{t}$ with the $k$ th typical element $\left(F_{t, k}-S_{t}\right) / S_{t}$. The vector process $X_{1}$ can be thought of as a stationary stochastic process. To facilitate the analysis, also define $w_{t}^{\prime}=\varepsilon_{t+1}\left(1, X_{t}^{\prime}\right)$. Then, $w_{t}$ can also be assumed to be a covariance stationary stochastic process with $K+1$ dimensional covariance matrix $\Theta=E\left(w_{i} w_{f}^{\prime}\right)$. Denote the typical element of $\Theta$ by $\theta_{i j}$. 
The actual data are sampled from the $w_{t}$ process. Imagine that the first observation on a regressor, $x_{1}$, corresponds to a contract with $K$ days to maturity, the second observation is on a contract with $K-1$ days to maturity, etc. At the $K$ th observation, there is one day to maturity, and the next observation begins the second contract with $K$ days to maturity. If there are $K$ days in all the contracts and $N$ total contracts in the sample, the total number of observations is $T=N K$.

In order to determine how $\Omega$ corresponds to certain terms of the elements of $\Theta$, we write out the terms in the expression:

$$
\begin{aligned}
\Omega= & \lim _{T \rightarrow \infty}\left(\frac{1}{T}\right) E\left\{\left(\begin{array}{c}
\varepsilon_{2} \\
\varepsilon_{2} x_{1}
\end{array}\right) \sum_{t=1}^{T}\left(\varepsilon_{t+1}, \varepsilon_{t+1} x_{t}\right)+\cdots\right. \\
& \left.+\left(\begin{array}{c}
\varepsilon_{T+1} \\
\varepsilon_{T+1} x_{T}
\end{array}\right) \sum_{t=1}^{T}\left(\varepsilon_{t+1}, \varepsilon_{t+1} x_{t}\right)\right\} .
\end{aligned}
$$

Since $E\left(\varepsilon_{t+1} \mid \varepsilon_{t}, \varepsilon_{t-1}, \ldots, x_{t}, x_{t-1} \ldots\right)=0$, only contemporaneous terms will be non-zero in (26). In terms of the elements of $w_{l}^{\prime}=\left(w_{1, t}, \ldots, w_{K+1, t}\right)$, the expression in (26) can be rewritten as

$$
\Omega=\lim _{N \rightarrow \infty}\left(\frac{1}{N K}\right) E\left\{\sum_{n=1}^{N} \sum_{k=1}^{K}\left|\begin{array}{c}
w_{1,(n-1) K+k} \\
w_{K+2-k,(n-1) K+k}
\end{array}\right|\left|\begin{array}{c}
w_{1,(n-1) K+k} \\
w_{K+2-k,(n-1) K+k}
\end{array}\right|\right\} .
$$

Hence,

$$
\Omega=\left(\frac{1}{K}\right) \sum_{k=1}^{K}\left|\begin{array}{cc}
\theta_{1,1} & \theta_{1, k+1} \\
\theta_{k+1,1} & \theta_{k+1, k+1}
\end{array}\right| .
$$

In (28) $\Omega$ is an average covariance of the $w_{t}$ process. It is straightforward to demonstrate that the $\Omega_{T}$ in (25) is a consistent estimator of $\Omega$ in (28). ${ }^{7}$ A similar argument can be used to demonstrate that $D_{T}$ is a consistent estimator of $\operatorname{plim}\left(Z^{\prime} Z / T\right)$, where convergence again requires the number of days within a contract to be fixed and the number of contracts to grow large. Convergence in this case is again to a type of average covariance of the $w_{1}$ process. $^{8}$

\footnotetext{
${ }^{7}$ Because the asymptotic distribution depends on the number of contracts growing large, the degrees of freedom in the analysis using daily futures data are inherently less than the number of observations.

"Samuelson (1976) explores the properties of the variance of changes in futures prices for models with no risk premium and stationary spot prices. He demonstrates that the variance of the change in futures prices must eventually damp as the number of periods till maturity increases, but for a certain number of periods near maturity, variability may 'transiently' reverse its direction. A nice feature of the current analysis is its ability to handle the inherent conditional heteroscedasticity present in sequences of futures prices.
} 
The results of this estimation procedure are presented in table 1. The period of estimation is from 1 June 1973 to 8 December 1983. Daily data were followed for the September 1973 contract until it expired on 17 September. The next observation on the dependent variable used the futures price on September 18 for the December 1973 contract. The right-hand-side variable was constructed from the futures price on 17 September for the same contract. Data were sampled in this manner to produce 2420 daily total observations.

For each currency in table 1 we test the null hypothesis that $\beta=1$, which allows for a constant risk premium. The data provide convincing evidence that the null hypothesis is violated. Only for the Deutschemark is the marginal level of significance of the test statistic larger than 0.014. Indeed, the results for the Japanese yen, the U.K. pound, the Canadian dollar and the Swiss franc provide particularly striking evidence against the null hypothesis of unbiased daily futures prices.

The next section of the paper considers estimation of the five equations as a system to allow tests of joint hypotheses.

\subsection{System estimation}

Some additional information can be gained by examining the five equations as a system since this allows joint tests of hypotheses across the various currencies. Simultaneous estimation of the ten parameters for the five currencies can be accomplished with a Generalized Method of Moments analogue to Zellner's (1962) seemingly unrelated regression. Also, since the GMM system is overidentified in this case, an additional test on the adequacy of the system is available. This is a joint test that the futures premiums at time $t$ for each of the other four currencies, the right-hand-side variables in the other equations, are not useful in predicting $\left(F_{t+1, k-1}-\right.$ $\left.S_{t}\right) / S_{t}$. As above, there is no need to assume a conditionally homoscedastic covariance matrix for the matrix of innovations as is the case with traditional seemingly unrelated regression.

Since it is now necessary to distinguish an observation on a single currency from the vector of observations on all five currencies, let $y_{t+1}^{j} \equiv\left(F_{t+1, k-1}^{j}-S_{t}^{j}\right) / S_{t}^{j}$ and $x_{t}^{j} \equiv\left(F_{t, k}^{j}-S_{t}^{j}\right) / S_{t}^{j}$, for $j=1, \ldots, 5$. Define the corresponding vectors $y_{t+1}$ and $x_{t}$ to be the observations on the five currencies at time $t$, and let $\varepsilon_{t+1}$ represent the vector of innovations in $y_{t+1}$. Similarly, define the vector function $h\left(y_{t+1}, x_{t}, \delta_{0}\right) \equiv \varepsilon_{t+1}$ with typical $j$ th element

$$
h_{j}\left(y_{t+1}, x_{t}, \delta_{0}\right)=y_{t+1}^{j}-\alpha_{j}-\beta_{j} x_{t}^{j}
$$

where $\delta_{0}$ is the ten element vector of parameters on $\alpha_{j}$ and $\beta_{j}$. 
The orthogonality conditions are now given by the fact that $\varepsilon_{t+1}$ has mean zero and is orthogonal to $x_{t}$. Let $z_{t}^{\prime} \equiv\left(1, x_{t}^{\prime}\right)$ be the six-element vector of instruments, and define the function $f$ by

$$
f\left(y_{t+1}, x_{t}, \delta\right)=h\left(y_{t+1}, x_{t}, \delta\right) \otimes z_{t} .
$$

As above, the null hypothesis implies:

$$
E\left[f\left(y_{t+1}, x_{t}, \delta_{0}\right)\right]=0,
$$

when $f$ is evaluated at the true parameter vector. This is a vector of thirty orthogonality conditions.

The GMM estimator of $\delta_{0}$ is again found by constructing the sample moment corresponding to (20) and by minimizing the criterion function in (21), where $W_{T}$ is now a $30 \times 30$ symmetric weighting matrix.

The system of equations can also be written as

$$
y=X \delta_{0}+\varepsilon,
$$

where

$$
\begin{aligned}
y^{\prime} & =\left(y_{1}^{1}, \ldots, y_{T}^{1}, \ldots, y_{1}^{5}, \ldots, y_{T}^{5}\right), \\
\varepsilon^{\prime} & =\left(\varepsilon_{1}^{1}, \ldots, \varepsilon_{T}^{1}, \ldots, \varepsilon_{1}^{5}, \ldots, \varepsilon_{T}^{5}\right), \\
X & =\left|\begin{array}{ccccc}
X_{1} & 0 & 0 & 0 & 0 \\
0 & X_{2} & 0 & 0 & 0 \\
0 & 0 & X_{3} & 0 & 0 \\
0 & 0 & 0 & X_{4} & 0 \\
0 & 0 & 0 & 0 & X_{5}
\end{array}\right|,
\end{aligned}
$$

and $X_{j}$ is the $T \times 2$ matrix of observations of $\left(1, x_{t}^{j}\right)$. If the matrix of instruments is written as

$$
Z=I \otimes\left|\begin{array}{c}
z_{1}^{\prime} \\
\vdots \\
z_{T}^{\prime}
\end{array}\right| .
$$

where $I$ is an identity matrix of dimension five, the sample orthogonality conditions are

$$
g_{T}(\delta)=Z^{\prime}(y-X \delta) / T,
$$


and the GMM criterion function is

$$
J_{T}(\delta)=(1 / T)^{2}(y-X \delta)^{\prime} Z W_{T} Z^{\prime}(y-X \delta) .
$$

This is minimized by choosing

$$
\delta_{T}=\left(X^{\prime} Z W_{T} Z^{\prime} X\right)^{-1} X^{\prime} Z W_{T} Z^{\prime} y .
$$

The estimate of the asymptotic covariance matrix for $\sqrt{ } T\left(\delta_{T}-\delta_{0}\right)$ is

$$
V\left(\delta_{T}\right)=\left(D_{T}^{\prime} W_{T} D_{T}\right)^{-1},
$$

where $D_{T}=Z^{\prime} X / T$. Hansen (1982) demonstrates that the optimal choice of $W_{T}$ is

$$
W_{T}=\left[\left(\frac{1}{T}\right) \sum_{t=1}^{T}\left(\hat{\varepsilon}_{t} \otimes z_{t}\right)\left(\hat{\varepsilon}_{t} \otimes z_{t}\right)^{\prime}\right]^{-1}
$$

where $\hat{\varepsilon}_{t}$ is a consistent estimate of $\varepsilon_{t}$.

Tests of joint hypotheses such as all $\beta_{j}$ are equal to one or all area equal can be conducted by writing the constraint as $R \delta_{r}=r$ and employing a Wald test. From the asymptotic distribution theory underlying (35) we know that

$$
\left(R \delta_{T}-r\right)^{\prime}\left[R V\left(\delta_{T}\right) R^{\prime} / T\right]^{-1}\left(R \delta_{T}-r\right)
$$

is distributed as a chi-square random variable with degrees of freedom equal to the row dimension of $R$.

The system estimation of $\delta_{0}$ is presented in table 2. Notice that, as is often the case with seemingly unrelated regression, the parameter estimates have not changed in a particularly dramatic way, but the standard errors of the estimates have all fallen. Since the parameter estimates of the slope coefficients are also slightly smaller, there is now even stronger evidence that each $\beta_{j}$ is not equal to one. The largest marginal level of significance of this test is only 0.0003 for the Canadian dollar. All other currencies have marginal levels of significance for this test that are smaller than 0.0001 . The joint test that all $\beta_{j}$ are equal to one is a chi-square statistic with five degrees of freedom. The value of the test statistic in this case is 81.2828 which also corresponds to a marginal level of significance smaller than 0.0001 . Hence, this hypothesis is strongly rejected by the data at conventional levels of significance. The test of the hypothesis that all the $\beta_{j}$ are equal is a chi-square statistic with four degrees of freedom. The value of the statistic is 11.8578 . This indicates that the hypothesis of equality of coefficients is rejected by the data at marginal levels of significance greater than 0.0184 . 
Table 2

Full sample system estimates

\begin{tabular}{lcccll}
\multicolumn{5}{c}{$\left(F_{t+1, k-1}^{j}-S_{t}^{j}\right) / S_{l}^{j}=\alpha_{j}+\beta_{j}\left[\left(F_{t, k}^{j}-S_{t}^{j}\right) / S_{i}^{j}\right]+\alpha_{t+1}^{j}, j=1, \ldots, 5}$. & \\
\hline Currency & $\hat{\alpha}_{j}$ & $\hat{\beta}_{j}$ & $R^{2}$ & Test $\beta_{j}=1$ & SEE \\
\hline 1. Japanese yen & 0.0001 & 0.9303 & 0.72 & 25.3290 & 0.0063 \\
& $(0.0001)$ & $(0.0139)$ & & {$[0.0000]$} & \\
2. Deutschenuark & {$[0.3095]$} & {$[0.0000]$} & & & \\
& 0.0005 & 0.8665 & 0.45 & 47.0878 & 0.0063 \\
& $(0.0001)$ & $(0.0195)$ & & {$[0.0000]$} & \\
3. U.K. pound & {$[0.0007]$} & {$[0.0000]$} & & & \\
& -0.0003 & 0.9258 & 0.58 & 19.1229 & 0.0059 \\
& $(0.0001)$ & $(0.0170)$ & & {$[0.0000]$} & \\
4. Canadian dollar & {$[0.0197]$} & {$[0.0000]$} & & & \\
& -0.0001 & 0.9395 & 0.62 & 12.8669 & 0.0024 \\
& $(0.0001)$ & $(0.0169)$ & & {$[0.0003]$} & \\
5. Swiss franc & {$[0.0074]$} & {$[0.0000]$} & & & \\
& 0.0007 & 0.8940 & 0.53 & 38.5584 & 0.0075 \\
& $(0.0002)$ & $(0.0171)$ & & {$[0.0000]$} & \\
& {$[0.0000]$} & {$[0.0000]$} & & & \\
\hline
\end{tabular}

Notes: See table I. Test all $\beta_{j}=1, \chi^{2}(5)=81.2868[0.0000]$. Test of equality of $\beta_{j}, \chi^{2}(4)=$ $11.8578[0.0184]$. Test of overidentifying restrictions, $\chi^{2}(20)=54.6413[0.0000]$.

As an additional test of the restrictions implied by the specification that only a constant and the own value of $\left(F_{t, k}^{j}-S_{t}^{j}\right) / S_{t}^{j}$ are useful in predicting $\left(F_{t+1, k-1}^{j}-S_{t}^{j}\right) / S_{t}^{j}$, we calculate $T$ times the value of the minimized criterion function in (33). Hansen's (1982) Lemma 4.2 indicates that this value is distributed as a chi-square random variable with twenty degrees of freedom since this is the number of overidentifying restrictions in the estimation of the system (31). The value of the test statistic is 54.6413 which is greater than the value of a $\chi^{2}(20)$ associated with the 0.0001 marginal level of significance. Consequently, there is strong additional evidence that the unbiasedness hypothesis is not an appropriate characterization of the data: the other futures premiums would have been useful in predicting each of the dependent variables.

\subsection{Subsample results}

The work of Lucas (1976) serves as a warning that the above cconometric analysis is probably not structural in the sense that the estimated coefficients may depend upon such things as the government policies pursued by the different countries and changes in the source or type of technological disturbances that generate real growth and aggregative fluctuations. This is particularly true of changes in the variances of the underlying stochastic 
processes driving the system since these parameters will have a direct influence on the risk premium. An additional reason to investigate whether subperiods provide the same type of inference as the full sample is the possibility that agents may have had to learn about the new international monetary system after the abandonment of the Bretton Woods system in early 1973. It is also often argued in popular discussions that prices in speculative markets such as futures and options possess stochastic properties that correspond to theories of efficient markets only after the markets are mature. Both of these latter reasons suggest that the results from the first half of the sample might be different from the results of the second half of the sample.

The subsample results are presented in tables 3-6. Tables 3 and 5 present the single equation estimation for the first and second subsamples that corresponds to the single equation technique used in table 1 , and tables 4 and 6 present the respective subsample system estimation corresponding to the full sample results in table 2 .

There are several interesting differences across the two subsamples in the single equation estimations that are not present in the two system estimations. The single equation results in table 3 demonstrate evidence against the null hypothesis $\beta=1$ only for the Canadian dollar and the Deutschemark, while the single equation results for the second half of the sample in

Table 3

Subsample one single equation estimates

$\left(F_{t+1, k-1}-S_{t}\right) / S_{t}=\alpha+\beta\left[\left(F_{t, k}-S_{t}\right) / S_{t}\right]+E_{t+1}$.

\begin{tabular}{lccccc}
\hline Currency & $\hat{x}$ & $\hat{\beta}$ & $R^{2}$ & Test $\beta=1$ & SEE \\
\hline 1. Japanese yen & 0.0002 & 0.9785 & 0.87 & 1.0987 & 0.0043 \\
& $(0.0001)$ & $(0.0205)$ & & {$[0.2945]$} & \\
& {$[0.0995]$} & {$[0.0000]$} & & & \\
2. Deutschemark & 0.0004 & 0.8973 & 0.36 & 6.0396 & 0.0054 \\
& $(0.0002)$ & $(0.0418)$ & & {$[0.0140]$} & \\
& {$[0.0244]$} & {$[0.0000]$} & & & \\
3. U.K. pound & -0.0002 & 0.9620 & 0.66 & 2.0590 & 0.0049 \\
& $(0.0002)$ & $(0.0264)$ & & $(0.1513]$ & \\
4. Canadian dollar & {$[0.1777]$} & {$[0.0000]$} & & & \\
& -0.0001 & 0.9373 & 0.73 & 10.0443 & 0.0019 \\
& $(0.0001)$ & $(0.0198)$ & & {$[0.0015]$} & \\
5. Swiss franc & {$[0.0067]$} & {$[0.0000]$} & & & \\
& 0.0005 & 0.9477 & 0.47 & 1.7808 & 0.0062 \\
& $(0.0003)$ & $(0.0392)$ & & {$[0.1821]$} & \\
\hline
\end{tabular}

Notes: The sample period begins at 1 June 1973 and contains the first 1210 observations. Also, see table 1 . 
Table 4

Subsample one system estimates

$\left(F_{t+1, k-1}^{j}-S_{l}^{j}\right) / S_{1}^{j}=\alpha_{j}+\beta_{j}\left[\left(F_{t, k}^{j}-S_{1}^{j}\right) / S_{\imath}^{j}\right]+\varepsilon_{1+1}^{j}, j=1, \ldots, 5$.

\begin{tabular}{lccccc}
\hline Currency & $\hat{x}_{j}$ & $\hat{\beta}_{j}$ & $R^{2}$ & Test $\beta_{j}=1$ & SEE \\
\hline 1. Japanese yen & 0.0002 & 0.9509 & 0.87 & 7.8556 & 0.0030 \\
& $(0.0001)$ & $(0.0175)$ & & {$[0.0051]$} & \\
& {$[0.0538]$} & {$[0.0000]$} & & & \\
2. Deutschemark & 0.0006 & 0.8279 & 0.36 & 27.1591 & 0.0038 \\
& $(0.0002)$ & $(0.0330)$ & & {$[0.0000]$} & \\
& {$[0.0006]$} & {$[0.0000]$} & & & \\
3. U.K. pound & -0.0002 & 0.9553 & 0.66 & 3.6520 & 0.0035 \\
& $(0.0002)$ & $(0.0234)$ & & {$[0.0560]$} & \\
4. Canadian dollar & {$[0.1973]$} & {$[0.0000]$} & & & \\
& -0.0002 & 0.9337 & 0.73 & 11.9104 & 0.0014 \\
& $(0.0001)$ & $(0.0192)$ & & {$[0.0006]$} & \\
5. Swiss franc & {$[0.0080]$} & {$[0.0000]$} & & & \\
& 0.0007 & 0.8969 & 0.47 & 11.9732 & 0.0044 \\
& $(0.0002)$ & $(0.0298)$ & & {$[0.0005]$} & \\
\hline
\end{tabular}

Notes: See table 1. Test of all $\beta_{j}=1, \chi^{2}(5)=48.3672[0.0000]$. Test of equality of $\beta_{j}, \chi^{2}(4)=$ $12.8075[0.0123]$. Test of overindentifying restrictions, $\chi^{2}(20)=55.6371[0.0000]$.

Table 5

Subsample two single equation estimates $\left(F_{1+1, k-1}-S_{t}\right) / S_{t}=\alpha+\beta\left[\left(F_{t, k}-S_{t}\right) / S_{t}\right]+\varepsilon_{t+1}$.

\begin{tabular}{lccccc}
\hline Currency & $\hat{\alpha}$ & $\hat{\beta}$ & $R^{2}$ & Test $\beta=1$ & SEE \\
\hline 1. Japanese yen & 0.0005 & 0.8924 & 0.43 & 12.7688 & 0.0079 \\
& $(0.0003)$ & $(0.0301)$ & & {$[0.0004]$} & \\
2. Deutschemark & {$[0.1091]$} & {$[0.0000]$} & & & \\
& -0.0001 & 0.9540 & 0.48 & 1.3438 & 0.0068 \\
& $(0.0003)$ & $(0.0397)$ & & {$[0.2464]$} & \\
3. U.K. pound & {$[0.7787]$} & {$[0.0000]$} & & & \\
& -0.0002 & 0.8728 & 0.40 & 13.5555 & 0.0067 \\
& $(0.002)$ & $(0.0346)$ & & {$[0.0002]$} & \\
4. Canadian dollar & {$[0.2294]$} & {$[0.0000]$} & & & \\
& -0.0001 & 0.9438 & 0.50 & 3.0676 & 0.0028 \\
& $(0.0001)$ & $(0.0321)$ & & {$[0.0799]$} & \\
5. Swiss franc & {$[0.2010]$} & {$[0.0000]$} & & & \\
& 0.0005 & 0.9141 & 0.51 & 7.0330 & 0.0086 \\
& $(0.0004)$ & $(0.0325)$ & & {$[0.0080]$} & \\
& {$[0.1829]$} & {$[0.0000]$} & & & \\
& & & &
\end{tabular}

Notes: The sample period ends at 8 December 1983 and contains the last 1210 observations. Also, see table 1. 
Table 6

Subsample two system estimates

\begin{tabular}{lccccc}
\multicolumn{5}{c}{$\left(F_{i+1, k-1}^{j}-S_{t}^{j}\right) / S_{i}^{j}=\alpha_{j}+\beta_{j}\left[\left(F_{t, k}^{j}-S_{i}^{j}\right) / S_{t}^{j}\right]+f_{i+1}^{j}, j=1, \ldots .5}$. \\
\hline Currency & $\hat{\alpha}_{j}$ & $\hat{\beta}_{j}$ & $R^{2}$ & Test $\beta_{j}=1$ & SEE \\
\hline 1. Japanese yen & 0.0007 & 0.8562 & 0.43 & 30.1638 & 0.0056 \\
& $(0.0003)$ & $(0.0262)$ & & {$[0.0000]$} & \\
& {$[0.0152]$} & {$[0.0000]$} & & & \\
2. Deutschemark & 0.0004 & 0.8636 & 0.46 & 29.7165 & 0.0050 \\
& $(0.0002)$ & $(0.0250)$ & & {$[0.0000]$} & \\
3. U.K. pound & {$[0.4239]$} & {$[0.0000]$} & & & \\
& -0.0002 & 0.8664 & 0.40 & 23.8227 & 0.0047 \\
& $(0.0002)$ & $(0.0274)$ & & {$[0.0000]$} & \\
4. Canadian dollar & {$[0.2510]$} & {$[0.0000]$} & & & \\
& -0.0001 & 0.9492 & 0.50 & 2.9132 & 0.0020 \\
& $(0.0001)$ & $(0.0298)$ & & {$[0.0879]$} & \\
5. Swiss franc & {$[0.2867]$} & {$[0.0000]$} & & & \\
& 0.0010 & 0.8731 & 0.51 & 32.4438 & 0.0061 \\
& $(0.0003)$ & $(0.0223)$ & & {$[0.0000]$} & \\
& {$[0.0018]$} & {$[0.0000]$} & & & \\
& & & &
\end{tabular}

Notes: See table 5 . Test of all $\beta_{j}=1, \chi^{2}(5)=59.9767[0.0000]$. Test of equality of $\beta_{j}, \chi^{2}(4)=$ $6.8491[0.1441]$. Test of overidentifying restrictions, $\chi^{2}(20)=30.2505[0.0659]$.

table 5 indicate strong evidence against the null hypothesis only for the other three currencies, the Japanese yen, the U.K. pound, and the Swiss franc.

The system estimations tell a slightly different story. For subsample one the results in table 4 indicate strong evidence against the null hypothesis of $\beta=1$ for all currencies except for the U.K. pound which has an individual marginal level of significance of 0.056 . All the other currencies have marginal significance levels smaller than 0.0051 . The joint test that all $\beta_{j}$ are equal to one has a marginal level of significance smaller than 0.0001 . For subsample two the results in table 6 also indicate strong rejection of the null hypothesis $\beta_{j}$ equal to one except for the Canadian dollar which has a marginal level of significance equal to 0.0879 . For all other currencies the individual marginal levels of significance are smaller than 0.0001 , which is also larger than the significance level of the joint test that all $\beta_{j}$ are equal to one.

In the first subsample there is also strong evidence that the other futures premiums may be useful in predicting the dependent variables since the value of the test statistic for the twenty overidentifying restrictions has a value of 55.6371 which is larger than the $\chi^{2}(20)$ associated with the 0.0001 level of significance. For the second subperiod this strength of evidence that other data would have been useful in predicting the dependent variables is not present since the test of the overidentifying restrictions has a value of 30.2505 which corresponds to a marginal level of significance of 0.0659 . 


\section{Interpretation and summary}

The previous section provides some strong evidence that daily futures prices are not unbiased predictors of futures prices on the following day. This section examines the implications of these findings for the variability of daily risk premiums.

Following Fama (1984), (14) can be written as

$$
F_{t, k}=E_{t}\left(F_{t+1, k-1}\right)+P_{t, 1},
$$

which defines the one-day risk premium as the expected profit on a short position in the futures market. The transformation of variables to induce stationarity in (16) produces a normalized risk premium:

$$
\left(F_{t, k}-S_{t}\right) / S_{t}=E_{t}\left[\left(F_{t+1, k-1}-S_{t}\right) / S_{t}\right]+p_{t, 1},
$$

where $p_{t, 1} \equiv P_{t, 1} / S_{t}$. Then, the slope coefficient $\beta$ in (17) can be described as

$$
\begin{aligned}
\beta= & C\left[\left(F_{t+1, k-1}-S_{t}\right) / S_{t} ;\left(F_{t, k}-S_{t}\right) / S_{t}\right] / V\left[\left(F_{t, k}-S_{t}\right) / S_{t}\right] \\
= & \left\{V\left[E_{t}\left(F_{t+1, k-1}-S_{t}\right) / S_{t}\right]\right. \\
& \left.+C\left[E_{t}\left(\left(F_{t+1, k-1}-S_{t}\right) / S_{t}\right) ; p_{t, 1}\right]\right\} / V\left[\left(F_{t, k}-S_{t}\right) / S_{t}\right] .
\end{aligned}
$$

The average estimated value of $\beta$ in table 2 is approximately 0.9 , and this provides an indication that $V\left[E_{t}\left(\left(F_{t+1, k-1}-S_{t}\right) / S_{t}\right)\right]$ is greater than $V\left(p_{t, 1}\right)$. To see this, notice in (40) that subtracting one from two times $\beta$ gives an estimate of the difference between the variances of $E_{t}\left[\left(F_{t+1, k-1}-S_{t}\right) / S_{t}\right]$ and $p_{t, 1}$ expressed as a proportion of the variance of the futures premium, $\left(F_{t, k}-S_{t}\right) / S_{t}$. The calculation is:

$$
\begin{aligned}
2 \hat{\beta}-1 & \left.=\left\{V\left[E_{t}\left(\left(F_{t+1, k-1}-S_{t}\right) / S_{t}\right)\right]-V\left(p_{t, 1}\right)\right\} / V\left[\left(F_{t, k}-S_{t}\right) / S_{t}\right)\right] \\
& =0.8
\end{aligned}
$$

with a standard error of approximately 0.04 . Consequently, the data indicate much more variability in $E_{t}\left[\left(F_{t+1, k-1}-S_{t}\right) / S_{t}\right]$ than in $p_{t, 1}$.

As noted in the Introduction, Fama (1984) and Hodrick and Srivastava (1986), using monthly data, document that variability in the risk premium in the one-month forward foreign exchange market across a number of currencies is greater than the variability of the one-month expected rate of depreciation. We next examine if it is possible to reconcile the findings of the monthly studies with those reported here. 
Discussion of these issues is facilitated by considering the logarithmic counterpart to (39) where lower-case letters represent natural logarithms of their upper-case counterparts:

$$
f_{t, k}-s_{t}=E_{t}\left(f_{t+1, k-1}-s_{t}\right)+p_{t, 1}
$$

where $p_{t .1}$ now represents the logarithmic risk premium as in Fama (1984). A regression of $\left(f_{t+1, k-1}-s_{i}\right)$ on a constant and the futures premium, $\left(f_{t, k}-s_{t}\right)$, produces a slope coefficient similar to $\beta$ in (40) which is denoted $\beta_{1}$ to indicate a one-day forecast. in

Now consider a regression of $\left(f_{t+2, k-2}-s_{t}\right)$ on a constant and $\left(f_{t, k}-s_{t}\right)$ as

$$
f_{t+2, k-2}-s_{t}=\alpha_{2}+\beta_{2}\left(f_{t, k}-s_{t}\right)+\varepsilon_{t+2,2},
$$

and decompose the dependent variable as

$$
f_{t+2, k-2}-s_{t}=\left(f_{t+2, k-2}-f_{t+1, k-1}\right)+\left(f_{t+1, k-1}-s_{t}\right) \text {. }
$$

Consequently, since $E_{t}\left(p_{t+1,1}\right)=-E_{t}\left(f_{t+2, k-2}-f_{t+1, k-1}\right)$, we have

$$
\begin{aligned}
\beta_{2}= & \beta_{1}-\left\{C\left[p_{t, 1} ; E_{t}\left(p_{t+1,1}\right)\right]\right. \\
& \left.+C\left[E_{t}\left(f_{t+1, k-1}-s_{t}\right) ; E_{t}\left(p_{t+1,1}\right)\right]\right\} / V\left(f_{t, k}-s_{t}\right) .
\end{aligned}
$$

Generalizing (43)-(45) to forecasts for $H$ days ahead gives:

$$
\begin{aligned}
\beta_{H}= & \beta_{1}-\left\{C\left[p_{t, 1} ; \sum_{h=1}^{H} E_{t}\left(p_{t+h, 1}\right)\right]\right. \\
& \left.+C\left[E_{t}\left(f_{t+1, k-1}-s_{t}\right) ; \sum_{h=1}^{H} E_{t}\left(p_{t+h, 1}\right)\right]\right\} / V\left(f_{t, k}-s_{t}\right) .
\end{aligned}
$$

If the nature of the time series properties of the data is that the daily risk premiums are highly positively autocorrelated and they are either positively correlated with $E_{t}\left(f_{t+1, k-1}-s_{t}\right)$ or not particularly negatively correlated, the estimated $\beta_{H}$ falls as we increase the forecast interval. This allows the variability of the risk premium to become larger relative to that of the expected rate of depreciation as the forecast interval increases, which allows for a reconciliation of the findings using daily and monthly data.

Empirical support for this interpretation can be obtained by examining the specification:

$$
\left(F_{t+30, k-30}-S_{t}\right) / S_{t}=\alpha+\beta\left(F_{t, k}-S_{t}\right) / S_{t}+c_{t+30},
$$


which is done in table 7 with the GMM system estimation. There are 115 non-overlapping observations in this analysis. On comparing tables 2 and 7 , we find that the coefficient estimates for the five currencies have fallen substantially. For example, for the Canadian dollar the slope coefficient has fallen from 0.94 to 0.08 while that for the Swiss franc has fallen from 0.89 to 0.19 . Notice from (40) that the change in coefficients implies that the variability of the one-month risk premium has increased relative to that of the one month expected rate of depreciation compared to the daily data. Although we do not conduct formal tests, it appears that the monthly coefficients are significantly different from the daily ones. The standard errors further indicate rejection of the null hypothesis $\beta_{j}=1$ at below the 0.0001 marginal level of significance for the Japanese yen, the Canadian dollar, and the Swiss franc, at the 0.0007 level for the U.K. pound, and the 0.0655 level for the Deutschemark. Only the Deutschemark coefficient is within two standard deviations of unity. The test that all of the $\beta_{j}$ are equal to one has a value of 46.5306 which corresponds to a marginal level of significance smaller than 0.0001 . If the distributions of the test statistics are appropriate, this is very strong evidence against the null hypothesis.

Of course, an alternative reconciliation of the findings recognizes that the application of asymptotic distribution theory is more appropriate the larger is the sample size. The ten years of daily data in this study provide a sample

Table 7

Monthly data system estimates

\begin{tabular}{lccccc}
\multicolumn{5}{c}{$\left(F_{i+30, k-30}^{j}-S_{f}^{j}\right) / S_{i}^{j}=\alpha_{j}+\beta_{j}\left[\left(F_{1, k}^{j}-S_{f}^{j}\right) / S_{i}^{j}\right]+\varepsilon_{i+30}^{j}, j=1, \ldots, 5}$. \\
\hline Currency & $\hat{\alpha}_{j}$ & $\hat{\beta}_{j}$ & $R^{2}$ & Test $\beta_{j}=1$ & SEE \\
\hline 1. Japanese yen & 0.0001 & 0.4552 & 0.03 & 15.6610 & 0.0317 \\
& $(0.0026)$ & $(0.1377)$ & & {$[0.0000]$} & \\
& {$[0.9752]$} & {$[0.0009]$} & & & \\
2. Deutschemark & -0.0020 & 0.5613 & 0.03 & 3.3927 & 0.0338 \\
& $(0.0029)$ & $(0.2382)$ & & {$[0.0655]$} & \\
3. U.K. pound & {$[0.4944]$} & {$[0.0184]$} & & & \\
& -0.0059 & 0.3691 & 0.03 & 11.4073 & 0.0256 \\
& $(0.0023)$ & $(0.1868)$ & & {$[0.0007]$} & \\
4. Canadian dollar & {$[0.0091]$} & {$[0.0482]$} & & & \\
& -0.0035 & 0.0786 & 0.00 & 16.8086 & 0.0122 \\
& $(0.0010)$ & $(0.2247)$ & & {$[0.0000]$} & \\
5. Swiss franc & {$[0.0003]$} & {$[0.0727]$} & & & \\
& 0.0036 & 0.1875 & 0.00 & 19.6647 & 0.0417 \\
& $(0.0037)$ & $(0.1832)$ & & {$[0.0000]$} & \\
& {$[0.3365]$} & {$[0.3061]$} & & & \\
\hline
\end{tabular}

Notes: There are 115 non-overlapping observations. Also, see table 1 . Test of all $\beta_{j}=1$, $\chi^{2}(5)=46.5306[0.0000]$. Test of equality of $\beta_{j}, \chi^{2}(4)=4.9459$ [0.2929]. Test of overidentifying restrictions, $\chi^{2}(20)=28.128[0.1064]$. 
of 2420 observations, whereas the cumulation of these data into changes over $H$ days provides $2420 / H$ non-overlapping observations. The degrees of freedom in the analysis may be increased by employing all the data as was done in Hansen and Hodrick (1980), but one is still left with inherently many fewer degrees of freedom.

Korjaczyk (1985) uses bootstrap techniques and Monte Carlo simulations in his study of the forward market in an attempt to assess the validity of his asymptotic distribution theory. He concludes that the fat-tailed nature of the dependent variable in financial studies such as this one may mean that convergence to the asymptotic distribution may be slower than is implied by the theory. His simulations indicate that the asymptotic distribution may understate the probability of large values of the test statistics in sample sizes such as his 89 monthly observations.

One problem with Korajczyk's simulations involves his treatment of the right-hand-side variables. Bootstrap and Monte Carlo techniques typically employ assumptions that the regressors are fixed in repeated samples or are strictly exogenous. In the bootstrap [see Efron (1982)] a new set of dependent variables is constructed by sampling with replacement from the empirical error distribution by adding the errors to the regressors whose coefficients are constrained by the null hypothesis. If the regressors are merely predetermined endogenous variables, such as technique does not generate new future right-hand-side variables whose values would be simultaneously determined with realizations of the current errors. The degree to which this problem invalidates the simulation results is unknown, but it is clearly an area where interesting research could be done.

This study documents a rejection of the hypothesis that foreign currency futures prices are unbiased predictors of futures prices on the following day. Such a finding is consistent with the findings of studies of the forward foreign exchange market and the fact that there is little difference between forward prices and futures prices on days when they can be compared. Reconciliation of the implied variabilities of risk premiums and expected rates of currency depreciation from the studies of daily futures prices and monthly forward prices is less straightforward. Daily futures prices imply variability of risk premiums that is smaller than variability of expected rates of depreciation while the opposite is found with monthly data. One interpretation of these findings is that daily risk premiums are highly positively autocorrelated. Additional research on the time series properties of risk premiums appears warranted if this explanation is to be confirmed.

\section{References}

Bilson, J.F.O., 1981, The speculative efficiency hypothesis, Journal of Business 54, July, 435-452.

Black, F., 1976, The pricing of commodity contracts, Journal of Financial Economics 3, Jan.,/March, 167-179. 
Cornell, B. and M. Reinganum, 1981, Forward and futures prices: Evidence from the foreign exchange markets, Journal of Finance 36, Dec., 1035-1045.

Cox, J., J. Ingersoll and S. Ross, 1981, The relation between forward prices and futures prices, Journal of Financial Economics 9, Dec., 321-346.

Cumby, R.E. and M. Obstfeld, 1981, A note on exchange-rate expectations and nominal interest differentials: A test of the Fisher hypothesis, Journal of Finance 36, June, 697-704.

Cumby, R.E. and M. Obstfeld, 1984, International interest-rate and price-level linkages under flexible exchange rates: A review of recent evidence, in: J.F.O. Bilson and R.C. Marston, eds., Exchange rate theory and practice (National Bureau of Economic Research, Cambridge, MA), 121-151.

Cumby, R.E., J. Huizinga and M. Obstfeld, 1983, Two-step two stage least squares estimation in models with rational expectations, Journal of Econometrics 21, April, 333-355.

Domowitz, I. and C. Hakkio, 1985, Conditional variance and the risk premium in the foreign exchange markel, Journal of International Economics 19, Aug., 47-66.

Dooley, M. and J. Shafer, 1983, Analysis of short-run exchange rate behavior: March, 1973 to November 1981, in: D. Bigman and T. Taya, eds., Exchange rate and trade instability (Ballinger, Cambridge, MA), 43-69.

Efron, B., 1982, The jackknife, the bootstrap, and other resampling plans (Philadelphia, Soc. Indus. and Appl. Math.).

Fama, E., 1984, Forward and spot exchange rates, Journal of Monetary Economics 14, Nov., 319-338.

French, K.R., 1983. A comparison of futures and forward prices, Journal of Financial Economics 12, Nov., $311-342$.

Hansen, L.P., 1982, Large sample properties of generalized method of moments estimators, Fconometrica 50, July, 1029-1054.

Hansen, L.P. and R.J. Hodrick, 1980, Forward exchange rates as optimal predictors of future spot rates: An econometric analysis, Journal of Political Economy 88, Oct., 829-853.

Hansen, L.P. and R.J. Hodrick, 1983, Risk averse speculation in the forward foreign exchange market: An econometric analysis of linear models, in: J.A. Frenkel, ed.. Exchange rates and international macroeconomics (National Bureau of Economic Research, Cambridge, MA), $113-142$.

Hansen, L.P. and K.J. Singleton, 1982, Generalized instrumental variables estimation of nonlinear rational expectations models, Econometrica 50, Sept., 1269-1286.

Hodrick, R.J. and S. Srivastava, 1984, An investigation of risk and return in forward foreign exchange, Journal of International Money and Finance 3, April. 5-29.

Hodrick, R.J. and S. Srivastava, 1985, Foreign currency fulures, National Bureau of Economic Research Working paper no. 1743.

Hodrick. R.J. and S. Srivastava, 1986, The covariation of risk premiums and expected future spot exchange rates, Journal of International Money and Finance 5, March, S5-S21.

Hsieh, D.A., 1984, Tests of rational expectations and no risk premium in lorward exchange markets, Journal of International Economics 17, Aug., 173-184.

Jagannathan, R., 1983, Three essays on the pricing of derivative claims, Ph.D. dissertation, Carnegie-Mellon University.

Jagannathan, R., 1985, An investigation of commodity futures prices using the consumptionbased intertemporal capital asset pricing model, Journal of Finance 40, Mar., 175-191.

Korajczyk, R.A., 1985. The pricing of forward contracts for foreign exchange, Journal of Political Economy 93, April, 346-368.

Lucas, R.E. Jr., 1976, Econometric policy evaluation: A critique, in: K. Brunner and A.H. Meltzer, eds., The Phillips curve and labor markets, Vol. 1 of the Carnegie-Rochester conference on public policy (Amsterdam, North-Holland), 19-46.

Lucas, R.E. Jr., 1982, Interest rates and currency prices in a two-country world, Journal of Monetary Economics 10, Nov., 335-360.

Lucas, R.E. Jr., 1984, Money in a theory of finance, in: K. Brunner and A.H. Meltzer, eds., Essays on macroeconomic implications of financial and labor markets and political processes, Vol. 21 of the Carnegie-Rochester conference on public policy (Amsterdam, NorthHolland), 9-45.

Mark, N.C., 1985, On time varying risk premia in the foreign exchange market: An econometric analysis, Journal of Monetary Economics 16, July, 3-18. 
Richard, S.F. and M. Sundaresan, 1981, A continuous time equilibrium model of forward prices and futures prices in a multigood economy, Journal of Financial Economics 9. Dec., 347-372.

Samuelson, P., 1965, Proof that properly anticipated prices fluctuate randomly, Industrial Management Review 6, Spring, 41-50.

Samuelson, P.. 1976, Is real-world price a tale told by the idiot of chance?. Review of Economics and Statistics 58, Feb., 120-123.

Singleton, K.J., 1985, Testing specifications of economic agents' intertemporal optimum problems in the presence of alternative models, Carnegie-Mellon University, manuscript.

Svensson, L.. 1985, Currency prices, terms of trade, and interest rates: A general equilibrium asset-pricing cash-in-advance approach, Journal of International Economics 18, Feb., 17-42.

Townsend, R., 1983, Asset return anomalies in a monetary economy, Carnegie-Mellon University, manuscript.

Zellner, A., 1962, An efficient method of estimating seemingly unrelated regressions and tests of aggregation bias, Journal of the American Statistical Association 57, 348-368. 